\title{
LA TRANSFORMACIÓN DE LAS NARRATIVAS Y PROYECTOS DE VIDA DE CUBANOS/AS DEL ORIENTE DE CUBA EN PUERTO RICO
}

\author{
Blanca Ortiz-Torres ${ }^{1}$ \\ Mario A. Rodríguez-Cancel \\ Universidad de Puerto Rico, Recinto de Río Piedras, Puerto Rico
}

\begin{abstract}
RESUMEN
Este trabajo constituye la segunda fase de un estudio que explora cómo cambian los proyectos de vida de los/as cubanos/as del Oriente de Cuba que han migrado a Puerto Rico en los últimos veinte años como resultado de las experiencias, relaciones y condiciones que han vivido en Puerto Rico. Nos propusimos: 1) explorar cómo se transforman los proyectos de vida y narrativas de este grupo de migrantes, 2) indagar la percepción de los/as participantes sobre las diferencias entre éstos/as y cubanos/as de otras regiones de Cuba y 3) explorar experiencias de discriminación y exclusión según experimentadas y descritas por los/as participantes en la primera fase. Otros/as investigadores/as han usado este acercamiento en estudios de migrantes con el objetivo de darles voz y visibilizarlos en las sociedades receptoras (Sonn, 2010).
\end{abstract}

\section{Palabras Clave}

migración, narrativas proyectos de vida, migrantes Cubanos en Puerto Rico

\begin{abstract}
This work constitutes the second phase of a study that explores how the life projects of Cubans from the East of Cuba who have migrated to Puerto Rico in the last twenty years change as a result of the experiences, relationships and conditions that have lived in Puerto Rico. We set out to: 1) explore how the life and narrative projects of this group of migrants are transformed, 2) investigate the perception of the participants about the differences between them and Cubans from other regions of Cuba and 3) explore experiences of discrimination and exclusion as experienced and described by the participants in the first phase. Other researchers have used this approach in migrant studies in order to give them a voice and make them visible in the host societies (Sonn, 2010).
\end{abstract}

\section{Keywords}

migration, life projects narratives, Cuban migrants in Puerto Rico

Correspondence about this article should be addressed to Blanca Ortiz-Torres.Email: b.ortiz@upr.edu 
Investigaciones como esta intentan promover métodos y acercamientos que legitimen las experiencias vividas por grupos excluidos por raza, género, clase o etnia (Sonn \& Green, 2006). Además, nos provee herramientas para interpretar la complejidad que subyace a las experiencias de las personas, partiendo de la premisa de que la realidad es construida socialmente, por lo cual los fenómenos que estudiamos se generan a partir de las relaciones de los/as protagonistas con sus diferentes contextos (Cardona \& Alvarado, 2015).

Se alude con frecuencia a cinco oleadas principales de migración cubana: la de los exilios históricos (1959-1962), la de los llamados "vuelos de la libertad" (1965-1973), la de Mariel (1980), la de los balseros (1994) y la post-soviética (Castro, 2002; Duany, 2015). Se han señalado factores que influyen en esta migración, entre éstos, procesos internos de la sociedad cubana (transformaciones políticas y económicas y contradicciones socio-clasistas), cadenas migratorias que se han ido estableciendo, desarrollo de redes sociales y la movilidad laboral (Aja, 2006). Varios autores señalan que la migración cubana de las últimas dos décadas está compuesta por personas más jóvenes que emigran principalmente por razones económicas (Aja, 1999; Ortiz-Torres \& Rodríguez-Cancel, 2019) y la ausencia de oportunidades de desarrollo profesional en Cuba (Duany, 2000). Se ha planteado también la posibilidad de que recientemente se estén dando migraciones temporeras y el retorno de cubanos/a jubilados/as a Cuba (Aja, 2006; Duany, 2000).

Para el 1940, se estima que había alrededor de 307 cubanos/a viviendo en Puerto Rico (Duany, 1992); de acuerdo con el Censo Comunitario del 2016, en Puerto Rico viven 14,405 cubanos/as. Esta cifra constituye una disminución en la cantidad cubanos/as en Puerto Rico (American Community Survey 2016; Censo de los Estados Unidos) cuando se compara con los/as 17, 860 registrados/as en el 2010. Actualmente los/as cubanos/as comprenden aproximadamente el $0.4 \%$ de la población en Puerto Rico, que en este momento es de 3.5 millones de habitantes. Muchos llegan en tránsito hacia Estados Unidos, sin embargo, un número sin determinar ha permanecido y se ha establecido en Puerto Rico.

\section{Diferencias regionales entre cubanos/as viviendo en Cuba}

Además de las diferencias conocidas entre migrantes cubanos/as dependiendo de la ola migratoria a la que pertenece, nos parece que existen diferencias entre los cubanos/as, según la región de Cuba en la que residían (o con la que se identifican) al momento de salir del país. Estas diferencias parecen estar vinculadas principalmente a factores económicos, raciales, culturales y lingüísticos (Bodenheimer, 2009; Fúster \& Ortiz-López, 2012). Ortiz López y Fúster han examinado las diferencias lingüísticas entre los/as cubanos del Oriente de Cuba y aquello/as nacidos y residentes de otras regiones (Ortiz, 1999; Fúster \& Ortiz-López, 2013). Según Fúster y Ortiz-López (2013) los habaneros/as poseen más prestigio que los orientales entre la población cubana, entre otras razones porque estos últimos son percibidos como menos blancos y menos educados/as.

Fúster y Ortiz-López (2012), consideran que el lenguaje, el fenotipo, la ideología política y el status socio-económico juegan un papel importante al momento de evaluar la aceptación y el prestigio entre los/as cubanos/as, adscribiéndose connotaciones negativas a "lo Oriental". La investigación existente sugiere que, en Cuba, las personas blancas aún se perciben como superiores (Colas, 2010; Duharte \& Santos, 1997). La presencia de un mayor número de personas negras en Oriente puede ser explicada por las diversas corrientes migratorias que se localizaron en esa región. Por ejemplo, hubo un influjo de haitianos/as en el siglo XVIII (Ortiz-López, 1999) como resultado de la Revolución Haitiana, que se asentaron principalmente en las regiones de Santiago de Cuba, Guantánamo y Camagüey. Además, emigraron esclavos libertos desde la región occidental hacia Oriente y el desarrollo de la industria 
azucarera en las primeras décadas del siglo XX atrajo corrientes migratorias procedentes de Haití, Jamaica y otras Antillas británicas (Venegas 2001; Giovanetti, 2018).

En las últimas décadas, ha habido una gran migración de cubanos/as de otras provincias a la Habana, particularmente orientales, buscando mejores oportunidades de empleo (Bodenheimer, 2009). Esta situación ha sido vista por muchos habaneros/as como un "asalto negro" a la ciudad (Bodenheimer, 2009). Fúster \& López (2012), encontraron que un $86 \%$ de los orientales que se han establecido en la Habana, tenían un nivel de escolaridad entre educación primaria y secundaria básica.

\section{Los/as cubanos/as en Puerto Rico}

En el caso de Puerto Rico, Duany y sus colaboradores/as habían llamado la atención en la década de los 90 a la complejidad del fenómeno de la migración cubana en Puerto Rico, particularmente la relación de estos con la sociedad receptora. En aquel momento estos autores/as observaban cómo los/as cubanos/as en Puerto Rico manifestaban una cubanía distinta a la de aquellos/as que emigraban a los Estados Unidos y que, al menos, existe ambivalencia entre los puertorriqueños/as en cuanto a su percepción y su relación con los/as cubanos.

Nos parece que la naturaleza de la migración cubana a Puerto Rico ha cambiado y que las personas del Oriente cubano que se han localizado en Puerto Rico en los últimos veinte años son distintas a las descritas por investigadores/as en la década de los 90. Ya en el 2005, Eckstein señalaba que la migración de los 90' es más pragmática y responde a razones distintas a las de oleadas anteriores, destacando que esta no es de carácter ideológico, sino centrada principalmente en el bienestar de la familia y en un segundo plano, lo económico. Castro (2002) coincide con este planteamiento y añade que los/as migrantes de la última ola hacia Estados Unidos, tienden a ser más jóvenes.

En el estudio exploramos los procesos de adaptación en territorio puertorriqueño, cómo se manifiestan y se transforman sus narrativas y cómo se transforman sus proyectos de vida. Exploramos las narrativas para comprender las historias de los/as participantes (Domínguez \& Herrera, 2013) y entender los contextos sociales en los que se desarrollan las mismas. Estudiamos cómo reflexionan los/as participantes en torno a sus proyectos de vida (Domínguez \& Herrera, 2013) incluyendo su cotidianidad y su visión de la relación con la cultura que los recibe, sus metas y objetivos futuros (Domínguez y Herrera, 2013). Conocer las formas en que estas personas describen su experiencia nos permite entender variables relacionales y las subjetividades que se construyen a partir de éstas, lo que podría facilitar las interacciones entre la sociedad receptora y los/as migrantes.

\section{Método}

Esta es la segunda fase de una investigación cualitativa. En esta segunda fase realizamos nueve entrevistas semi-estructuradas $(n=9)$. Para la primera fase llevamos a cabo un grupo focal y tres entrevistas semi-estructuradas. Las preguntas guías de la entrevista surgieron de los hallazgos obtenidos del análisis de los grupos focales, cuyos resultados han sido descritos anteriormente (Ortiz-Torres \& Rodríguez-Cancel, 2019). En este trabajo presentamos hallazgos que surgen de las entrevistas en la segunda fase.

Los/as participantes fueron reclutados a partir de nominaciones y sugerencias realizadas por lo/as participantes en los grupos focales. Las personas nominadas autorizaron a las personas nominadoras a que nos proveyeran su número telefónico. Con esta información contactamos a los/as potenciales participantes para explicarle la naturaleza y objetivos del estudio. Una vez la persona aceptaba participar se acordaba un lugar privado para realizar la entrevista. Antes de comenzar la entrevista, el/la entrevistador/a leía en voz alta la hoja de consentimiento y aclaraba cualquier duda que pudiera tener el/la participante. El protocolo de investigación fue autorizado por el Comité Institucional para la Protección de Sujetos Humanos del Recinto de Río Piedras de la Universidad de Puerto Rico.

Las entrevistas semi-estructuradas tenían una duración de aproximadamente una hora y media y fueron transcritas para facilitar el proceso de análisis de contenido y la identificación sistemática de las 
temáticas dentro de los textos. El proceso de análisis de contenido y la identificación sistemática de las temáticas dentro de los textos, nos "permite investigar el contenido de las "comunicaciones" mediante la clasificación en "categorías" de los elementos o contenidos manifiestos de dicha comunicación o mensaje" (Aigneren,1999). La entrevista recoge datos demográficos y variables como salario, lugar de origen, grado académico más alto y estado civil. La sección cualitativa explora temas como percepción de los/as habaneros/as, imaginarios sobre Puerto Rico antes de emigrar, percepción de los/as puertorriqueños/as y cambios y transformaciones de proyectos de vida.

\section{Descripción de los/as participantes}

\section{Resultados}

Entrevistamos a nueve participantes $(n=9)$ cuyas edades fluctúan entre 29 y 69 años. Seis se identifican como hombres y tres como mujeres y solo uno informa estar soltero al momento de la entrevista. Cinco de nuestros/as participantes son originarios/as de la provincia de Granma, uno/a de Holguín y tres de Santiago de Cuba. Ocho informaron que tienen hijos/as, de los cuales dos indicaron que estos/as no viven en Puerto Rico (uno está en Cuba y otro en Canadá).

Han vivido en Puerto Rico entre cuatro y dieciocho años. La mayoría de los/as participantes tiene grados universitarios y/o grados técnicos y la mitad ha cursado algún tipo de grado universitario en Puerto Rico. La ubicación laboral en Puerto Rico es, en términos generales, similar a la que tenían en Cuba: principalmente trabajos profesionales y/o administrativos. Ocho de nuestros/as participantes se encontraban empleados/as al momento de ser entrevistados/as y uno terminaba estudios de postgrado.

E1 75\% de los/as participantes devenga un salario mensual de $\$ 4,501$ o más. El salario promedio de los/as puertorriqueños es de aproximadamente \$1,633 mensuales (Census Bureau, 2016), lo que implica que nuestros/as participantes devengan casi tres veces más que el salario mensual promedio de los/as puertorriqueños/as

\section{El tránsito de Oriente hacia Puerto Rico: Extranjeros en su propio país}

La mayoría de nuestros/as participantes refieren que la práctica de personas del Oriente cubano de mudarse a otra región antes de emigrar es muy o bastante común. La razón principal para salir de Oriente es económica, seguida por la aspiración a una mejor educación. Estas razones fueron las mismas que, posteriormente, les hizo emigrar de Cuba.

Aproximadamente la mitad de nuestra muestra ha vivido en la Habana; los/as que no lo han hecho respondieron que, aunque no han vivido allí, sí la visitaban regularmente, para ver a familiares, de paseo, o para realizar cualquier tipo de trámite, ya que la mayoría de los trámites "importantes" se realizan en la capital. En muchos casos el proceso migratorio comienza trasladándose a La Habana porque, según estos/as, es más fácil salir del país desde La Habana, ya que

...las oportunidades para salir del país, las mayores oportunidades, y no eran una ni dos, eran varias, tú veías muchas opciones, eran en La Habana, y el primer paso generalmente de las personas era, emigrar a La Habana y después entonces irse, a donde fuera, generalmente Estados Unidos. (Mujer, 31 años, Santiago de Cuba)

Nuestros/as participantes se perciben distintos/as a cubanos/as de otras regiones de su país, especialmente habaneros/as y a los que viven en Estados Unidos. Con frecuencia expresaron sentirse extranjeros/as y discriminados/as en su propio país, particularmente cuando los/as llaman de forma despectiva 'palestinos'. Uno de nuestros participantes expresó que la visión de los/as habaneros/as sobre los orientales es:

...bien despectiva, bien discriminada, es como que, en ocasiones 'palestinos', eh, te daban como raro, te miraban bien por encima del hombro, todo lo negativo que pueda surgir, quizás no de todo el mundo, pero de la gran mayoría sí. (Hombre, 39 años, Yara) 
Los participantes expresan cómo en la Habana existen ideas estereotipadas sobre los/as Orientales; específicamente sobre su forma de hablar, su color de piel, su forma de vestir y sus capacidades intelectuales. Uno de los participantes compartió una experiencia en una tienda en La Habana:

...fui a comprar algo y llamé a algo de una manera, un objeto, una fruta como la llamábamos en Oriente y cuando la muchacha la escuchó, yo, yo soy una persona que estoy bien al tanto de lo que pasa a mi alrededor y veo cuando la muchacha llama a la otra, "ven échatelo para que tu veas como dice tal fruta, pregúntale' entonces la muchacha vino a preguntarme, pero yo manejé la situación con un poquito de humor, pero me dolió... (Hombre, 38 años, Manzanillo)

La exclusión puede ser tanta que muchos/as adoptan el "acento habanero" para que no los perciban como Orientales e "incluso los habaneros que criticaban a los orientales, en su momento pudieron ser orientales".

Otro de los participantes expuso que la discriminación a la cuales son sometidos/as, se da también por parte de instancias gubernamentales y compartió la siguiente experiencia vivida en la milicia:

Este..., una de ellas fue que, los habaneros eh, le daban más pase, los trataban mejor allí en lo militar, los orientales pues tu veías que siempre los tenían trabajando en la parte más fuerte del trabajo, pues iba para los orientales, y como habaneros más dóciles, ese se veía, se veía el, el, el trato, que se veía que era más, más suave hacia ellos y más fuerte hacia nosotros. No me daban pase, se lo daban a ellos, ellos... ellos son de ahí pero no importa, nosotros tenemos un derecho a pase, aunque fuéramos a dar una vuelta y muchas personas de ahí tenían familiares que podían quedarse también, y salir. (Hombre, 39 años, Yara)

Describen a los/as habaneros/as como: triviales, como que valoran más las cosas materiales, muy competitivos, maliciosos y egocéntricos, y que se creen superiores. Para nuestros/as participantes los/as habaneros/as "piensan que Cuba es La Habana". Uno de los participantes lo articuló de la siguiente forma:

En general eh, el habanero mira al resto de la isla como que, como más atrasado, eh... quizás culturalmente. Como que se creen un poco como que... más, como decir, eh... más importantes que el resto de la isla. Tienden un poco a discriminar, nos ven como la gente del campo aquí, como la gente de la isla. (Hombre, 34 años, Santiago)

También perciben a los/as habaneros/as como vagos/as, especuladores/as, interesados/as en vestir bien más que en comer bien; aunque advierten que no todos/as son así y que hay habaneros/as buenos/as, profesionales y trabajadores/as.

$\mathrm{Al}$ preguntarle a los/as participantes con quienes se relacionaban más en La Habana, todos/as mencionaron que con orientales. Uno de los participantes expuso que:

Se daba porque... um, no existían las bases económicas y estructurales don.. donde, una persona que viaja a la capital pueda encontrar un espacio para alojarse, de manera costo efectiva, y el mecanismo más rápido y expedito era el alojamiento solidario de familiares y amigos de Oriente... Y porque realmente como había tanta distancia psicológica, cultural, y geográfica entre Oriente y La Habana, más allá de los encuentros profesionales, uno no tiene amigos habaneros, así que uno no encuentra fácilmente posibilidades de hospedarse o alojarse en casas de habanero... (Hombre, 45 años, Manzanillo) 


\section{La vida en Puerto Rico}

Las narrativas de las personas entrevistadas sobre su vida en Puerto Rico expresan nostalgia por su país, aprecio por la acogida recibida por parte de puertorriqueños/as, la necesidad de trabajar duro en Puerto Rico y la posibilidad de crecimiento personal y profesional. Una de las participantes expuso que le hubiese gustado de antemano saber "... de todo lo que se paga, o sea que del IVU [impuesto sobre ventas] y to' de todo eso, me tenían que haber hablado antes, para ir preparándome...". Otro/a expresa que ha tenido que aprender a vivir en un país capitalista, en el que cosas que parecen cotidianas y dadas para los/as puertorriqueños/as, en su caso, requieren un proceso de aprendizaje y adaptación. El participante verbalizó lo siguiente:

Para comer arroz y habichuelas yo estaba preparado, para comer chuletas, para bailar, para cualquier cosa porque en ese sentido somos iguales, para pedir en un McDonald's no. Para que tengas una idea, para comprar en una tienda no, para trabajar con una ATM [cajero automático] no, para adaptarme a que las transacciones electrónicas, para todo eso pues yo no estaba preparado, eso pues me costó más trabajo pues, yo no estaba preparado, mi sociedad no me preparó para eso. (Hombre, 38 años, Manzanillo)

En Puerto Rico han tenido que desarrollar nuevas formas de relacionarse y de comportarse, porque las normas sociales son distintas. Uno/a de los/as participantes expuso que los/as puertorriqueños/as se ofenden con facilidad, que ha tenido que aprender a cómo dirigirse hacia ellos/as. Algunos/as indican que han transformado su forma de vestir, su forma de conducirse en escenarios de trabajo y en relaciones formales e informales. Sin embargo, la mayoría describe que se ha adaptado a la sociedad puertorriqueña sin mayores contratiempos y solo uno de los participantes expresó haber sentido algún discrimen por parte de algunos puertorriqueños/as.

A diferencia de su experiencia en La Habana, los/as participantes sienten que son percibidos/as por los/as puertorriqueños como trabajadores/as, preparados/as profesionalmente, que vienen a ayudar al país y que son solidarios/as. Uno/a de los/as participantes compartió lo siguiente, “...en Cuba me decían como que, los puertorriqueños veían a los cubanos en, de personas emprendedoras, personas que trabajan mucho, que echaban pa' lante, que eran personas luchadoras". Estas respuestas fueron consistentes en todos/as nuestros/as participantes, quienes, en sentido general, expresan que los/as puertorriqueños/as tienen una muy buena impresión de los/as cubanos/as.

Aun cuando algunos/as tienen sentimientos de desarraigo, la apertura de los/as puertorriqueños/as ha facilitado el proceso de adaptación y muchos/as de los/as participantes dicen sentirse como verdaderos/as puertorriqueños/as. Uno/a de los/as participantes indicó que sintió “...que a mí me quitaron de Cuba y me pusieron en Puerto Rico y yo no me enteré". Otro participante que expresó que inicialmente se le hizo difícil adaptarse a los nuevos modos de relacionarse en Puerto Rico, subrayó la importancia de los lazos familiares en el proceso de adaptación:

Me siento como si viviera aquí de toda la vida, a pesar de eso que yo he dicho...Porque he llegado a comprender muchas cosas, del ser humano y, sobre todo, de mi familia, de mi mujer, de mis hijos que se sienten bien, y los veo felices, se han adaptado bien, y donde ellos estén bien yo estoy bien también (Hombre, 69, Antillas)

Aunque en general, tienen relaciones positivas con los/as puertorriqueños/as, siguen socializando principalmente con cubanos/as, aunque de manera informal y no necesariamente con organizaciones formales de cubanos/as en Puerto Rico. La mayor parte de los/as participantes mantienen comunicación frecuente con Cuba y, en general, viajan a Cuba al menos una vez al año. 


\section{Proyectos de vida}

La mayoría de las personas entrevistadas expresa que ha experimentado cambios en sus proyectos de vida. Algunos de estos cambios incluyen: aspiración a formación profesional, establecimiento de metas a largo plazo y planificación para el retiro. Muchos/as de nuestros/as participantes expusieron que sus proyectos de vida se han mantenido consistentes, pero en Puerto Rico ven la oportunidad de desarrollarse profesionalmente, algo que en Cuba veían como imposible. Como expone una de las participantes “...el proyecto era crecer en el trabajo, pero no había manera. Ya de ahí, después que yo había llegado a ser contable, no había manera de ser otra cosa." Una de las participantes expuso lo siguiente:

...en Puerto Rico es que yo puedo aspirar a crecer profesionalmente porque como ser humano es algo que yo me propongo y no me lo puede impedir nadie, si yo quiero ser buen ser humano lo voy a ser, quiera quien no quiera. Pero, sin embargo, en lo profesional en Cuba no había manera de crecer, aquí, aunque haya que esforzarse mucho sin tener que pararle el pie encima a nadie, tú puedes llegar lejos. (Mujer, 50 años, Contramaestre)

Observamos que los proyectos de vida se han transformado, en la medida que las personas entrevistadas ven la posibilidad de progreso personal, familiar y económico. No obstante, uno/a de los/as participantes expresó que para entender las transformaciones en los proyectos de vida hay que tomar en consideración que "las sociedades son diferentes, las dos, la vida es diferente y la edad es diferente". En las narrativas de los/as participantes se destaca el sacrificio que hicieron para salir de Cuba, y los retos que enfrentaron y todavía enfrentan en Puerto Rico. Una de las participantes expuso que no se imaginaba lo intenso que iba a ser el proceso hasta que llegó a Puerto Rico:

Porque me tuve que enfrentar a muchas cosas, sabes. Nosotros llegamos para empezar de cero, con dos hijos pequeños. No es lo mismo una pareja porque uno come lo que sea, uno pasa lo que sea, pero uno cuando tiene hijos uno piensa primero en ellos. Y a pesar de que uno viene con la visión de que no es necesario tenerlo todo, pero si lo necesario, lo que tú necesitas para tu vida diaria. (Mujer, 50 años, Contramaestre)

Uno/as de los/as participantes reconoció que probablemente tenga que trabajar hasta que fallezca, pero que vive con la satisfacción de que pudo logra la meta que se había trazado: traer a su familia a Puerto Rico.

La mayoría de los participantes no tiene como proyecto migrar hacia los Estados Unidos. Varias razones explican esta decisión: han desarrollado un fuerte sentido de pertenencia a la sociedad puertorriqueña, perciben que tendrían dificultad en adaptarse al entorno cubano de Miami y aquellos/as que tienen hijos/as nacidos en Puerto Rico sienten que es en Puerto Rico donde quieren criarlos o continuar sus vidas con ellos/as.

\section{Factores que han facilitado la adaptación}

Nuestros/as participantes han reiterado de manera consistente que el proceso de adaptación a Puerto Rico fue bastante "fácil". Uno de los/as participantes lo articuló así: "La idiosincrasia, el idioma, la similitud de las personas, la bondad de la inmensa mayoría de los puertorriqueños, la bondad". Verbalizaron que los/as puertorriqueños/as acogen bien a los/as cubanos/as y manifiestan hacia estos/as una gran solidaridad, que facilita el proceso de adaptación. Uno de los participantes expresó lo siguiente:

Personas con las que trabajé, que me ayudaron a adaptarme en todos los trabajos que he hecho. Comencé trabajando en una panadería, luego en una oficina, después trabajando en la oficina comencé a estudiar. En la universidad me ayudaron muchísimo mis compañeros porque había cosas que no, era un medio en que no me movía mucho. Y después en los mismos hospitales en 
donde he trabajado y después incluido este centro donde estoy trabajando ahora. También mis compañeros puertorriqueños me han ayudado a adaptarme. (Hombre, 38 años, Manzanillo)

Mencionaron el progreso y las posibilidades de progreso como facilitadores de ese proceso. Muchos de nuestros/as participantes expusieron que entre sus razones para emigrar a Puerto Rico está la reunificación familiar, otro factor que ha facilitado el proceso de adaptación. Uno/a de los/as participantes expuso que "a lo mejor pues tener la familia, al tener la familia pues tienes como un apoyo, y al tener pues... eso aquí pues me ha sido más fácil". Otro de los participantes expresa que el apoyo familiar no es solo emocional, sino también instrumental para aprender a navegar en el nuevo contexto:

Bueno aparte de, como mencioné creo que orita, mi personalidad, el hecho de tener el... el amplio apoyo familiar, tu sabes mi familia ya estaba aquí y tú sabes quizás me, me dieron un 'lá' de cómo era que funcionaban las cosas, aparte del apoyo familiar en general tú sabes, creo que eso fue... fue fundamental, aparte de..., de la personalidad que tengo que yo soy bastante adaptable a las nuevas circunstancias, eh... y me integro también. [Hombre, 29 años, Yara]

Pareciese que la edad en la que los/as participantes emigraron de Cuba juega un papel importante en el proceso de adaptación. Mientras más edad tiene la persona al salir, mayor son los vínculos con Cuba y los sentimientos de desarraigo. Uno/a de los/as participantes que dice sentirse puertorriqueño, nos dijo que sus padres añoran e idealizan a Cuba y hablan constantemente de ese país. Uno/a de los/as participantes reflexiona sobre esto y ofrece su opinión: "eso se debe a que ellos tienen más raíces en Cuba porque vivieron la mayoría de sus vidas allí”.

\section{Factores que han dificultado la adaptación}

Algunos/as participantes identifican diferencias culturales como uno de los factores que han dificultado la adaptación, lo que parecería ser una contradicción a lo expresado antes cuando reconocen las similitudes que existen entre la cultura de Cuba y Puerto Rico. Algunos/as participantes exponen que han tenido que aprender a vivir en Puerto Rico, especialmente en lo que se refiere a interacciones sociales en diversos escenarios. Uno de lo participantes compartió lo siguiente sobre sus experiencias en su centro de trabajo:

...en verdad pues se aprende a tolerar, uno en Cuba pues tiene esta manera impulsiva quizás aquí hay que medirse mucho para hablar lo que tú dices, porque cualquier cosa es una falta de respeto, que allá pues tú lo encontrabas normal, ... en el trabajo por ejemplo pasé trabajo, pues cosas que en Cuba son normales pues aquí todo es una falta de respeto o es un... un acoso laboral es como algo, qué sé yo... diferente. (Mujer, 36 años, Yara)

\section{Diferencias entre los orientales en Puerto Rico versus los que viven en Estados Unidos}

La gran mayoría de nuestros/as participantes está de acuerdo en que los/as cubanos/as orientales viviendo en Puerto Rico y los/as que viven en Estados Unidos son diferentes. De acuerdo con ellos/as los/as que se van, especialmente para el área de Miami, manifiestan un "cubaneo" similar al que vivieron en La Habana. Estos/as siguen "especulando", que, de acuerdo con nuestros/as participantes, es aparentar que viven mejor de lo que sus condiciones le permiten.

Uno/a de los/as participantes expuso que muchos/as de los/as que se mudan a Estados Unidos en algunas ocasiones cambian en dirección negativa. Expresan que el cubano/a, habanero/a u oriental, que se muda para Hialeah, va a continuar viviendo "como si siguiera viviendo en La Habana". La manifestación de ese cubanía va a depender de si el contexto cercano es predominantemente cubano o estadounidense. Uno de los participantes compartió lo siguiente refiriéndose inicialmente a los cubanos en Puerto Rico:

Aquí no, aquí el cubano es diferente, cubano que se queda aquí es completamente diferente. Yo tengo una amiga que vive en Tampa, que casualmente me visitó hace una semana y ella me dice 
“... yo en Miami no viviría” y ella es de Oriente de donde era yo y yo le digo ¿por qué? Y ella me dice “... es que eso es un desastre, una competencia, eso es una cafrería lo que hay allî". Y yo se lo creo porque lo puedo ver en Facebook y a la hora que ellos viajan a Cuba y ellos le hacen ver al cubano como que 'yo estoy súper bien donde estoy, no me ha costado nada'... (Mujer, 50 años, Contramaestre)

Pocos/as participantes expusieron que estos/as no ven mayores diferencias entre los dos grupos, añadiendo que la gran mayoría de las personas que se van a Estados Unidos, lo hacen por procesos de reunificación familiar o porque ven mayores oportunidades de desarrollo en los Estados Unidos.

\section{Discusión}

Se ha estudiado con alguna frecuencia cómo los procesos de migración e inserción en la sociedad receptora inciden en la(s) identidad(es) de los/as que migran. Reconociéndose como construida socialmente, la identidad se transforma y se negocia en las interacciones con la cultura receptora (Sonn \& Lewis, 2009). En el caso de la mayoría de nuestros/as participantes primero se dio una migración interna del Oriente de Cuba a la Habana y luego la migración a Puerto Rico. En el primer caso, los retos enfrentados se caracterizaron con frecuencia por la exclusión y la discriminación por parte de los/as Habaneros (un "otro" que comparte su identidad por origen nacional); en el segundo caso, debían aprender a vivir en un sistema social y económico distinto, aunque con similitudes culturales (RodríguezCancel, 2018).

La exclusión percibida por parte de los/as habaneros/as durante su estadía en la Habana, resultó ser central para la subjetividad de muchos/as de los/as participantes. Esta dimensión ha sido estudiada por Rodríguez-Cancel (2018) en una investigación que encontró que las personas entrevistadas se sienten discriminados/as tanto por las políticas gubernamentales como por los/as habaneros/as. La negociación de la identidad en el contexto de la Habana está matizada por la caracterización discriminatoria que hacen de ellos/as muchos/as habaneros/as; es decir, personas de bajo nivel académico, pobres y güajiras.

Nuestros hallazgos sugieren que las narrativas y proyectos de vida de la muestra de migrantes estudiada se construyen principalmente alrededor de lo que identificaron como sus razones para salir de Cuba: progreso económico, crecimiento profesional y reunificación familiar. Con la migración han cambiado las opciones de desarrollo y aspiraciones personales y profesionales. Sus proyectos han incorporado la planificación para el retiro, viajar a otros países y seguir creciendo como profesionales.

Si se compara con otros grupos de migrantes en Puerto Rico, nuestro/as participantes narran un proceso, por lo general, positivo de inserción en la sociedad puertorriqueña, lo que puede explicarse en términos generales por el carácter privilegiado que tenía hasta hace poco la migración cubana en Estados Unidos y sus territorios. Reyes \& Sonn (2010), aluden a este proceso cuando señalan que "la membresía a grupos sociales particulares basadas en etnicidad, raza, género, permite acceso diferenciado de las personas al poder y a privilegios en diferentes contextos" (p.206). De acuerdo con sus narrativas, los entendidos de los/as puertorriqueños/as sobre lo que significa ser cubano/a del Oriente de Cuba, son distintos a los que nuestros/as participantes enfrentaron en su estadía en la Habana. En Puerto Rico nuestros/as participantes van construyendo una subjetividad distinta, basada en origen nacional que los/as representa como trabajadores/as, competentes y solidarios/as.

Martínez-Callaghan \& Gil-Lacruz (2017) han identificado cinco dimensiones que ayudan al proceso de inserción en el país receptor: (1) tener pareja, (2) interés en el país anfitrión, (3) experiencias en el lugar de trabajo, (4) cantidad de personas en sus redes sociales y, (5) el dominio del lenguaje del país anfitrión. Como vimos, la mayoría de nuestros/as participantes tiene pareja, se sienten muy a gusto en Puerto Rico, se han sentido apoyados en su centro de trabajo y obviamente, hablan español como en 
Puerto Rico. Aunque no tenemos información del tamaño de sus redes sociales, sabemos que se relacionan principalmente con otros/as Orientales y cubanos/as de otras regiones del país. Nos parece que un sexto elemento a considerar es la edad de la persona al momento de migrar. Cooper, Edsall, Riviera, Chartin \& Linstroth (2009) han documentado las "pertenencias ambivalentes" de cubanos/as migrantes y destacan que las experiencias de estos/as son distintas dependiendo de la edad al migrar, en buena medida porque representan diversos momentos políticos y económicos tanto para Cuba como para la persona migrante. Representan también, momentos evolutivos distintos que generarán barreras o facilitadores particulares.

Nuestros hallazgos confirman lo señalado antes por Staton-Salazar \& Spina (2003): los/as migrantes que participan en espacios sociales con sus coterráneos experimentan mayor sentido de pertenencia y de integración social, lo que facilita sus interacciones con las comunidades receptoras. Es decir, no se trata de excluirse de la cultura receptora relacionándose principalmente con otros/as migrantes de su país, sino de afianzar sus relaciones con sus compatriotas, con los que comparten historia, códigos particulares, así como formas de relacionarse y comportarse. Estas interacciones entre Orientales también facilitan la continuidad de las identidades culturales y el sentido de comunidad, importantes para el bienestar social, psicológico y para la adaptación al país receptor (Sonn, 2002).

Teniendo en cuenta que los procesos de migración conllevan la pérdida y ruptura de lazos comunitarios y familiares (Sonn, 2002), tanto las interacciones con otros/as cubano/as, como con puertorriqueños/as contribuyen a la afirmación de elementos de su identidad y a la revisión y posibles cambios de otros. Como señala Barrios-Villalobos (2010) es la exposición a diversas subjetividades lo que construye y reconstruye las identidades porque éstas tienen “...un carácter altamente intersubjetivo y relacional, en un marco de auto percepción de un sujeto en relación con los otros, dado que en esa relación opera el reconocimiento y la aprobación entre los miembros de una comunidad." (MercadoMondragón, 2008, p. 22)

\section{Conclusiones generales}

La muestra de participantes estudiada en esta investigación representa una migración distinta a las de otras olas migratorias de cubanos/as en Puerto Rico. La relación con la sociedad receptora, es decir, Puerto Rico es positiva, lo que permite una mayor afirmación de su identidad sociocultural. Las transformaciones en los proyectos de vida de los/as participantes se dan principalmente en los ámbitos de formación profesional e inserción laboral; se trata de un grupo que registra cambios en sus proyectos a corto y a largo plazo.

La posibilidad de reflexionar sobre la migración desde su experiencia, le permite a los/as participantes "rearticular su historia" (Sonn \& Lewis, 2009), construir su memoria individual y colectiva y fortalecer su sentido de comunidad. El sentido de comunidad también se transforma, porque la comunidad no está solo compuesta por cubanos/as orientales, sino que también por cubanos/as de otras regiones de ese país y puertorriqueños/as. La divulgación de estos hallazgos podría contribuir a visibilizar a este grupo de inmigrantes y a destacar sus aportaciones a la sociedad puertorriqueña.

Finalmente, los hallazgos señalan la necesidad de una investigación con una muestra más amplia, que permita documentar las particularidades y subjetividades de los/as migrantes cubanos/as del Oriente a Puerto Rico, además de un estudio comparativo entre Orientales que viven en Puerto Rico y los/as que viven en Estados Unidos. 


\section{Referencias}

Aigeneren, M. (1999). Análisis de Contenido: Una Introducción. La Sociología En Sus Escenarios,3, 152.

Aja, A. (2000). La emigración de Cuba en los años noventa.Cuban Studies, 30, 1-25.

Aja, A. (2006). La migración desde Cuba. Aldea Mundo, 11(22), 7-16.

Arias Cardona, A., \& Alvarado Salgado, S. (2015). Investigación narrativa: apuesta metodológica para la construcción social de conocimientos científicos. CES Psicología, 8 (2), 171-181.

Barrios Villalobos, V. A. (2010). La construcción de la identidad social de migrantes adolescentes. Revista De Educación Y Desarrollo,14, 39-43.

Bodenheimer, R. (2009). "La Habana no aguanta más": Regionalism in Contemporary Cuban Society and Dance Music. Musical Quarterly, 92, 210-241.

Castro, M. (2002). The New Cuban Immigration in Context. The North South Agenda, 58, 3-12.

Colas, H. (2010). Racismo Estructural en Cuba y Disidencia Política: Breves Antecedentes. Cuba in Transition,253-257.

Cooper, R., Edsall, D., Riviera, D., Chaitin, J., \& Linstroth, J. (2009). "My Country" / "This Country": Ambivalent Belongings of Cuban Americans in South Florida. Forum Qualitative Sozialforschung / Forum: Qualitative Social Research, 10(3). doi:http://dx.doi.org/10.17169/fqs10.3.1364

Domínguez De la Ossa, E., \& Herrera González, J. (2013). La investigación narrativa en Psicología: Definición y funciones. Psicología Desde El Caribe, 30(3)

Duany, J. (1992). Caribbean Migration to Puerto Rico: A comparison of Cubans and Dominicans. International Migration Review, 26(1), 46-66.

Duany, J. (2015). The Cuban Exodus: Growing Complexity and Diversity. Presentado en el Refugee Services Consultation.

Duharte, R., \& Santos, E. (1997). El fantasma de la esclavitud: Prejuicios raciales en Cuba y America Latina. Pahl-Rugenstein Verlag.

Eckstein, S. (2005). The Transformation of the Diaspora and the Transformation of Cuba. En J. S. Tulchin, L. Bobea, M. P. Espina, R. Hernández, \& E. Bryan (Eds.), Changes in Cuban Society Since the Nineties (pp. 207-227). Washington, DC: Woodrow Wilson International Center for Scholars.

Fúster, N. \& Ortiz-López (2012). Variación geolectal y percepciones lingüísticas en Cuba. (Tesis de maestría no publicada).

Martinez-Callaghan, J., \& Gil-Lacruz, M. (2017). Developing identity, sense of belonging and social networks among Japanese immigrants in Scotland and Spain. Asian and Pacific Migration Journal,26(2), 241-261. doi:10.1177/0117196817706034

Mercado-Mondragón, J. (2008). Las Consecuencias Culturales de la Migracion y Cambio Identitario en una Comunidad Tzotzil, Zinacantán, Chiapas, México. Agricultura, Sociedad Y Desarrollo,19-38.

Ortiz-López, L. (1999). La variante hispánica haitianizada en Cuba: otro rostro del contacto lingüístico en el Caribe. En A. Morales, J. Cardona, E. Forestieri \& H. López Morales, Estudios de lingüística hispánica. Homenaje a María Vaquero, pp. 428-456.

Ortiz-Torres, B., \& Rodríguez-Cancel, M. A. (2019). Una primera mirada a la migración de cubanos del Oriente de Cuba a Puerto Rico. Caribbean Studies,47(1), 125-142.

Rodríguez-Cancel, M. A. (2018). Micro-agresiones: Las Experiencias de Orientales Cubanos/as viviendo en Puerto Rico (Tesis de maestría no publicada). Universidad de Puerto Rico.

Sonn, C. (2002). Immigrant Adaptation Understanding the Process Through Sense of Community. En A. T. Fisher, C. C. Sonn, \& B. J. Bishop (Eds.), Psychological sense of community: Research, applications, and implications (pp. 205-222). New York: Kluwer Academic/Plenum.

Sonn, C. \& Lewis, R. (2009). Immigration and identity: The ongoing struggles for liberation. En M. Montero \& C. Sonn (Eds.) Psychology of liberation: Theory and Applications (pp. 115-133). 
Peace Psychology Books Series, DOI: 10.1007/978-0-387-85784-8_7. Springer Science + Business Media.

Sonn, C. (2010). Engaging with the Apartheid Archive Project: Voices from the South African Diaspora in Australia. South African Journal of Psychology, 40(4), 432-442.

Sonn, C. C., \& Green, M. J. (2006). Disrupting the dynamics of oppression in intercultural research and practice. Journal of Community \& Applied Social Psychology,16(5), 337-346. doi:10.1002/casp.877

Stanton-Salazar, R. D., \& Spina, S. U. (2003). Informal Mentors and Role Models in the Lives of Urban Mexican-Origin Adolescents. Anthropology and Education Quarterly,34(3), 231-254. doi:10.1525/aeq.2003.34.3.231

Reyes, M., \& Sonn, C. C. (2010). (De)colonizing Culture in Community Psychology: Reflections from Critical Social Science. American Journal of Community Psychology,47(1-2), 203-214. doi:10.1007/s10464-010-9378-x

U.S. Census Bureau (2016). ACS Demographic and Housing Estimates 2012-2016 American Community Survey 5-Year Estimates. Recuperado de https://factfinder.census.gov/faces/tableservices/jsf/pages/productview.xhtml?src=CF 